\title{
Retail Price Effects of Feed-in Tariff Regulation
}

\author{
Maria Teresa Costa* $\quad$ Elisa Trujillo-Baute*
}

\begin{abstract}
The feed-in tariff regulation is the wider spread promotion scheme used to encourage the take-up and development of generation from renewable energy sources in the EU, and the costs of resources devoted to this promotion are usually borne by final consumers. Two components of the electricity retail price are expected to be influenced by feed-in tariff regulation: the incentive to those firms producing electricity from renewable energy sources and the wholesale price of electricity. In this study we analyze the effects that feed-in tariff regulation has on electricity retail price for industrial consumers. This analysis is performed by estimating the relative intensity of the effects from the cost of incentives for electricity generation under the feed-in tariff and the electricity wholesale price over the Spanish industrial retail price. Especial attention is devoted to technologyspecific considerations, as well as short and long run effects. In general, results show that there is not a strong link between the retail and wholesale market for Spanish industrial consumers. Moreover, taking into account technology-specific characteristics, results indicates that an increase of solar generation leads to a higher increase in the industrial retail price than in the case of a proportional increase of wind generation. This implies that, when evaluating the feed-in tariff regulation impact on the industrial retail price, the cost of incentives effect prevails over the wholesale price effect, and this is stronger for solar than for wind generation.
\end{abstract}

Keywords: electricity prices; feed-in-tariff; retail market; wholesale market.

\footnotetext{
${ }^{*}$ Department of Public Economics, University of Barcelona \& Chair of Energy Sustainability - IEB (UB) FUNSEAM. Corresponding author: elisatrujillo@ub.edu
} 


\section{Introduction}

Within the European Union (EU) 2020 energy strategy, the Third Energy Package aimed to complete the liberalization process, and the Climate and Energy Package implemented the targets for 2020 (known as the "20-20-20" targets). One of the targets was raising the share of EU energy consumption produced from renewable resources to 20\% (Directive (2009/28/EC). EU countries embraced this target promoting the production of electricity from renewable energy sources (RES), and the feed-in tariff (FIT) regulation is the wider spread promotion scheme used to encourage the take-up and development of generation from RES. Basically, under the FIT regulation a specific price is guaranteed per electricity produced by generators of the targeted technologies.

In most EU countries the costs of resources devoted to promote the production of electricity from RES are borne by final consumers. Recent years' recession has made Europe's governments, industry and consumers worried about high energy prices, and some blame is attributed to climate policies in general and to FIT in particular. In Spain, around $8 \mathrm{Bn}$ Euros a year, on average, have been devoted to promote the production of electricity from RES during the last four years. This amount of resources represents around $12 \%$ of the industry GDP. Given that these costs are translated to final consumers through the electricity bill, it is worth thinking over the implications that this policy has on retail prices. Electricity is a highly relevant economic factor, therefore, policy and regulatory decisions affecting its price should be deeply analysed given the direct effect that energy prices have on the production costs of firms and, hence, in terms of welfare. However, there is no empirical assessment of the actual impact that this scheme has over final consumer (retail) prices.

Two components of the electricity retail price are expected to be influenced by FIT regulation; the incentive to those firms producing electricity from RES and the wholesale price of electricity. On the one hand, from the characteristics of the electricity wholesale price (WP) formation (merit of order) and the low marginal cost of renewable energy generation, the introduction of RES in the energy mix is expected to exert a downward pressure on the WP of electricity. This effect over the WP is represented on the Wholesale Market graph in Figure 1. On the other hand, from the regulatory design of the incentive mechanisms the FIT costs (FITC) are charged to the final electricity consumers. Hence, acting over the electricity retail price in opposite directions (see Retail Market graph in Figure 1), both components are functions of the proportion of renewable sources in the energy mix. Therefore, to assess the overall effect of RES promotion the research question is on the relative intensity that these two components exert over electricity retail prices. 
Figure 1: FIT Regulation Effects
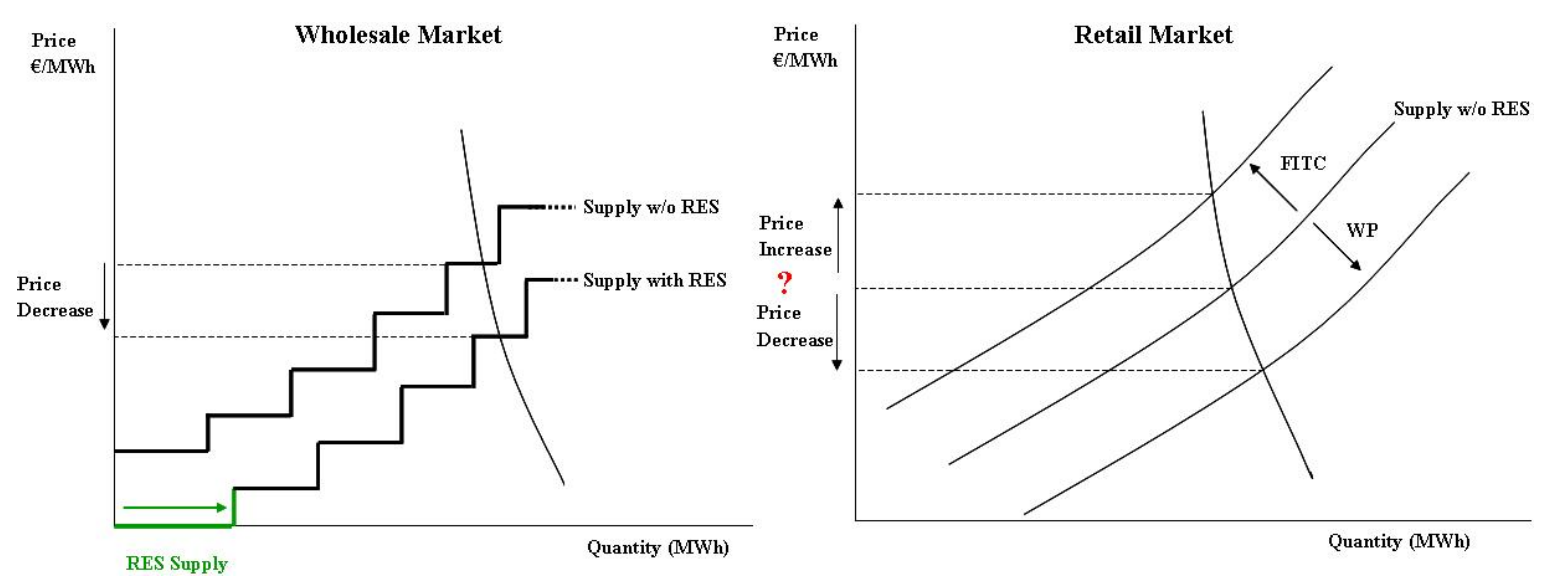

With the exceptions of Finland and The Netherlands where the FITC are completely financed by general taxes, in EU countries the costs of promoting RES are borne by final electricity consumers. Depending on the regulatory design, the FITC might be translated into the electricity prices by two basic ways; non-tax levies and pass down to end users of suppliers costs $(\mathrm{CEER}, 2013)^{1}$, and in both the FITC are translated to the retail price after the wholesale price is set. Hence, the more common regulatory design is one in which the FITC are borne by final consumers without impacting the wholesale price market formation mechanism. This, along with the data availability for Spain, and the fact that in the EU context Spain is one of the countries with the highest renewable power capacity ${ }^{2}$ (with Germany and Italy), wind power generation penetration (with Germany and Denmark), and solar power generation penetration (with Germany), are the main reasons why this study is applied to Spain.

In order to stimulate the development of certain technologies, the basic feature of FIT is to guarantee generators of the targeted technologies a specific price per electricity produced. In Spain the FIT is granted to generation from RES and cogeneration plants with an installed capacity below 50MW (this is the so called Special Regime -SR). To take into account that different technologies have different levels of development and generation costs, the supports are technology-specific granted. Figure 2 shows the yearly average FITC (in $€ / \mathrm{MWh}$ ) in Spain by technology during the last four years. While solar technology was granted with an average of $375 € / \mathrm{MWh}$ produced, in the case of wind and small hydro was an average of 83 $€ / M W h$, for cogeneration (COG) and other renewable the average FIT was $110 € / M W h$.

It is also important to highlight that wind and solar technologies make different contributions of electricity to the system during the day, which are characterized by different demand profiles. While wind power contribution is in relative terms higher during off-peak hours, the

\footnotetext{
${ }^{1}$ To be more precise, while the non-tax levies are used in Austria, Belgium, France, Ireland, Italy, Lithuania, Luxembourg, Slovenia, and Spain, the pass down to end users of suppliers costs is used in Belgium, Czech Republic, Germany, Greece, Hungary, Norway, Poland, Portugal, Romania, Sweden, and UK.

${ }^{2}$ Excluding hydropower.
} 
Figure 2: Yearly Average FITC (in $€ / M W h)$

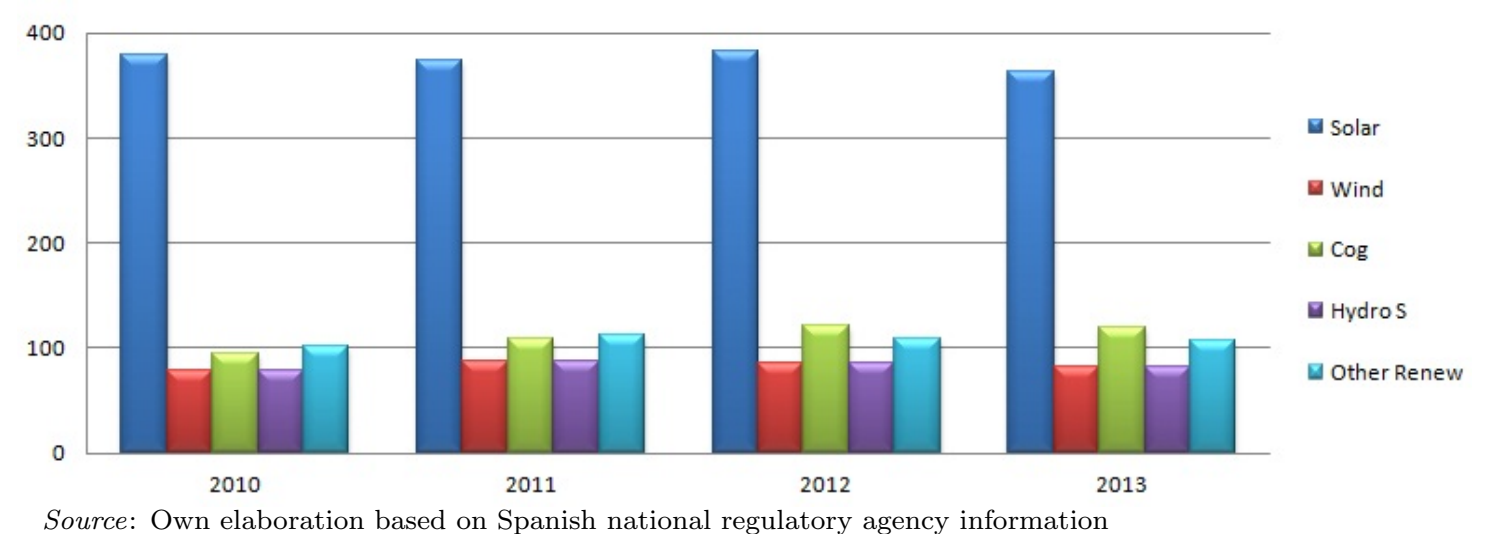

opposite happens with solar power which is generated during daylight (peak hours). Moreover, the technologies within the FIT scheme provided different contributions to the energy consumed (see Figure 3); while during the last years wind covered on average around $20 \%$ of the total load, solar covered $5 \%$ in the best case, small hydro only $3 \%$ or less, other renewable $2 \%$ or less, and COG (non-renewable) covered about $13 \%$ of the load. Hence, technology specific considerations are important not only from the FITC perspective but also on the WP perspective, and this is carefully taken into account in the empirical study presented here.

Figure 3: Yearly Average \% of Load

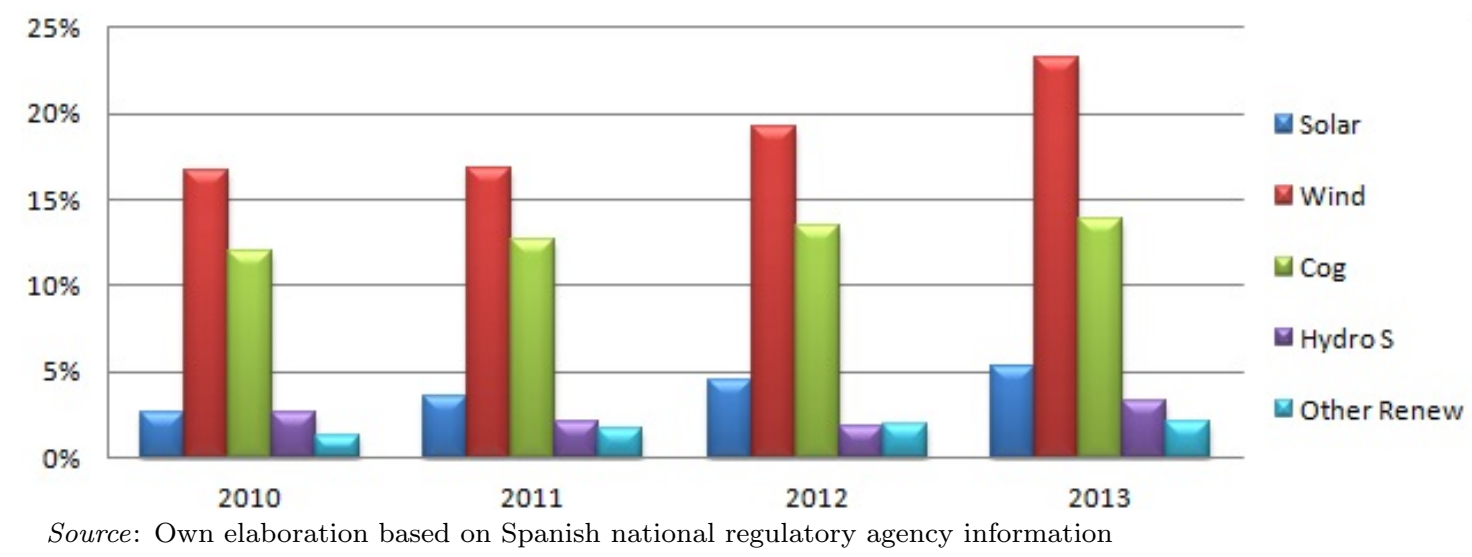

To the best of our knowledge, none of the previous work has assessed empirically from a disaggregated perspective the effect from both determinants (FITC and WP) on retail price. Therefore, this paper aims to contribute to the empirical analysis of the effect that the FIT regulation has over the electricity retail price for industrial consumers by quantifying the relative intensity of the FITC and the WP of electricity. Especial attention is devoted to technology-specific considerations, as well as short and long run effects. 
This article is organized as follows. Section 2 summarizes the links to the existing literature. Section 3 describes the data and models used to estimate the retail price effects of the feed-in tariff regulation. Section 4 presents the estimation and results of our analysis. Finally, section 5 discusses, interprets, and contextualizes our findings.

\section{Links to the existing literature}

Previous studies for different countries have analyzed (ex-ante and ex-post) the additional cost from supporting FIT, estimated the potential benefits from the merit of order effect, and compared aggregated figures of the potential cost savings from higher RES to direct costs of the FIT. Below we describe the main finding of these three closely related branches of the energy economics literature.

Numerous ex-ante studies calculate the additional cost from supporting schemes to electricity generated from RES. Ragwitz et al. (2007) predicted that it was necessary a steady rise of the average EU consumer price between $5.0 € / \mathrm{MWh}$ and $7.7 € / \mathrm{MWh}$ over the period 20052010 to finance the RES deployment. In the German case, Frondel et al. (2010) calculated (dividing the overall amount of FIT of about $9 \mathrm{Bn} €$ by the overall electricity consumption of $617 \mathrm{Bn} \mathrm{kWh}$ ) that in 2008 the price mark-up due to the FIT was about $7.5 \%$ of the average household electricity price. Using a quantitative electricity market model that accounts for factors such as oligopolistic behavior, emission trading, and restricted cross-border transmission capacities, Traber and Kemfert (2009) also find an upward price effect of the German FIT. Relatively few ex-post studies have analyzed the price effects of FIT regulation. Del Rio and Gual (2007) assess the effect of the Spanish FIT between 1999 and 2003 in terms of additional costs paid by consumers for renewables compared to conventional electricity (i.e. the share of RES promotion of the electricity bill). Their study finds that the additional cost for the consumer increased annually by $23 \%$ during the period considered.

As previously mentioned, some properties of RES generation could also potentially counteract the upward-price effect associated with FIT regulation. In the wholesale electricity market the supply curve is constructed by ordering the bids of all generators from lowest to highest. These bids should equate the marginal costs of the generators and, therefore, the supply curve reflects the aggregate marginal cost curve for the market (if no market power exists). The market price is set at the intersection of the supply and demand curves, and all generators with lower marginal costs serve demand receiving this uniform price. The introduction of technologies under the FIT tends to shift the supply curve to the right, due to its low marginal cost of generation, which pushes more expensive marginal plants (e.g. coal, combined cycle, petroleum, etc.) out of the market, and exerts a downward pressure on the wholesale price of electricity (see Wholesale Market graph in Figure 1). This is called the merit of order effect, a well documented feature of wholesale prices in context of FIT. 
Traber and Kemfert (2011), using a mixed complementary program computational model, find that higher wind supply reduces German market prices by more than 5\%. Gelabert et al. (2011), using a multivariate regression model of daily average Spanish electricity prices for 2005 to 2009, also find that a marginal increase of 1 GWh of electricity from RES and COG is associated with a reduction of $1.9 € / \mathrm{MWh}(3.7 \%)$ in wholesale electricity prices. Following a similar methodological approach Würzburg et al. (2013) find that in Germany and Austria electricity price fell by roughly $1 € / \mathrm{MWh}$ (around $2 \%$ of the electricity price) for each additional GWh of average daily renewable electricity generation between July 2010 and June 2012 .

Finally, there are studies that, in an attempt to account for both effects, compare the potential cost savings from higher RES to direct costs of the FIT with either or both effects considered at an aggregated level. This is the case of the study by Sensfub et al. (2008), which offers a detailed analysis of the price effects of renewable electricity generation on German wholesale prices between 2001 and 2006. When comparing the computed cost savings due to RES feed-in to the total costs of the FIT in 2006 they find that the cost savings outweighed the total costs. Similarly, Saenz de Miera et al. (2008), through a simulation analysis for the Spanish wholesale price, find that when comparing the simulated reduction of the wholesale price of electricity as a result of more wind generation with the total yearly support for wind generation, there are net saving costs for consumers from the FIT scheme. Likewise, Ciarreta et al. (2014) compared the computed savings from the merit of order effect with the yearly total amount of subsidies in Spain. The authors find that while the cost savings exceed the subsidies between 2008 and 2009, the opposite was true between 2010 and 2012. Also for the Spanish case, Burgos-Payan et al. (2013) compared the aggregated cost and benefits from the FIT system over the period 2008-2009 and find that the magnitude of both effects are roughly counterbalanced.

Our research is related with the above literature, more closely related to the last group given that we account for both effects, although from a disaggregated perspective. More precisely, through the estimation of three econometric models, this paper contributes to the empirical assessment of the effect that the FIT regulation has over the industrial retail price of electricity by quantifying its sensibility to the incentives for electricity generation under the FIT and the electricity wholesale price. Especial attention is devoted to technology-specific considerations. In the next section we present the empirical approach and the data used to perform the analysis of the effects that the FIT regulation has on Spanish electricity retail prices for industrial consumers. 


\section{Data and methods}

The empirical assessment of the effect that the FIT regulation has over electricity retail price (RP) has been developed through the estimation of a RP equation which allows us to quantify the relative intensity of the effects from both the FITC and the WP of electricity. This assessment is performed in a two steps strategy using weekly data. First, we estimate an inverse supply equation Eq.(1) where WP as function of the energy supply mix and the load (equilibrium quantity), and a FITC equation Eq.(2) capturing the effect that the daily electricity production by RES and COG has on the cost per unit of electricity consumption. Second, we introduce the estimates of WP and FITC (along with additional controls) into the RP equation Eq.(3) to evaluate the relative intensity of both components. Below we describe the models and data used to estimate the retail price effects of the feed-in tariff regulation.

$$
\begin{gathered}
\begin{array}{c}
\Delta W P_{t}=\beta_{0}+\beta_{1} \Delta W P_{t-1}+\beta_{2} \Delta \operatorname{Load}_{t}+\beta_{3} \Delta M i x_{t} \\
+\Delta \beta_{4} Y_{t}+\Delta \beta_{5} Q_{t}+\Delta \beta_{6} M_{t}+\Delta \beta_{7} W_{t}+\epsilon_{1 t}
\end{array} \\
\sigma_{1 t}^{2}=\delta_{0}+\delta_{1} \epsilon_{1 t}^{2} \\
\Delta F I T C_{t}=\lambda_{0}+\lambda_{1} \Delta F I T C_{t-1}+\lambda_{2} \Delta M i x_{t} \\
+\lambda_{3} \Delta Y_{t}+\lambda_{4} \Delta Q_{t}+\lambda_{5} \Delta M_{t}+\lambda_{6} \Delta W_{t}+\lambda_{7} \epsilon_{2 t-1}+\epsilon_{2 t} \\
\begin{array}{c}
\Delta R P_{t}= \\
\quad \alpha_{0}+\alpha_{1} \Delta R P_{t-1}+\alpha_{2} \Delta \widehat{W P}_{t}+\alpha_{3} \Delta \widehat{F I T C}_{t} \\
+\alpha_{4} \Delta Y_{t}+\alpha_{5} \Delta Q_{t}+\alpha_{6} \Delta M_{t}+\alpha_{7} \Delta W_{t}+\epsilon_{3 t}
\end{array}
\end{gathered}
$$

We analyzed the FIT effect on the wholesale market price $\left(W P_{t}\right)$ in Eq. (1) following the empirical strategy of estimation in differences as Gelabert et al. (2011) and Würzburg et al. (2013). In addition to the load $\left(\Delta \operatorname{Load}_{t}\right)$ and the electricity generation by energy source $\left(\Delta M i x_{t}\right.$ which includes wind, solar, other renewable, cogeneration, combined cycle, nuclear, coal and hydro), we introduce an autoregressive component $\left(\Delta W P_{t-1}\right)$ to capture dynamic effects, and an ARCH variance to account for the increasing volatility effects that are observable in the first difference of the $W P_{t}$ series (see Figure 4).

The residuals in Eq. (1) are defined as an autoregressive process where all $\epsilon_{1 t}$ are of the form $\epsilon_{1 t}=Z_{t} \sigma_{1 t}^{2}$ with $Z_{t v}(0,1)$, and $D_{v}(0,1)$ is the probability density function of the residuals with zero mean and unit variance. Eq. (1.1) represents the variance equation of the ARCH process. The wholesale price data were obtained from market operator (OMEL) and data on electricity generation by energy source were obtained from the transmission system operator (REE). 
Figure 4: Wholesale Price (first differences)

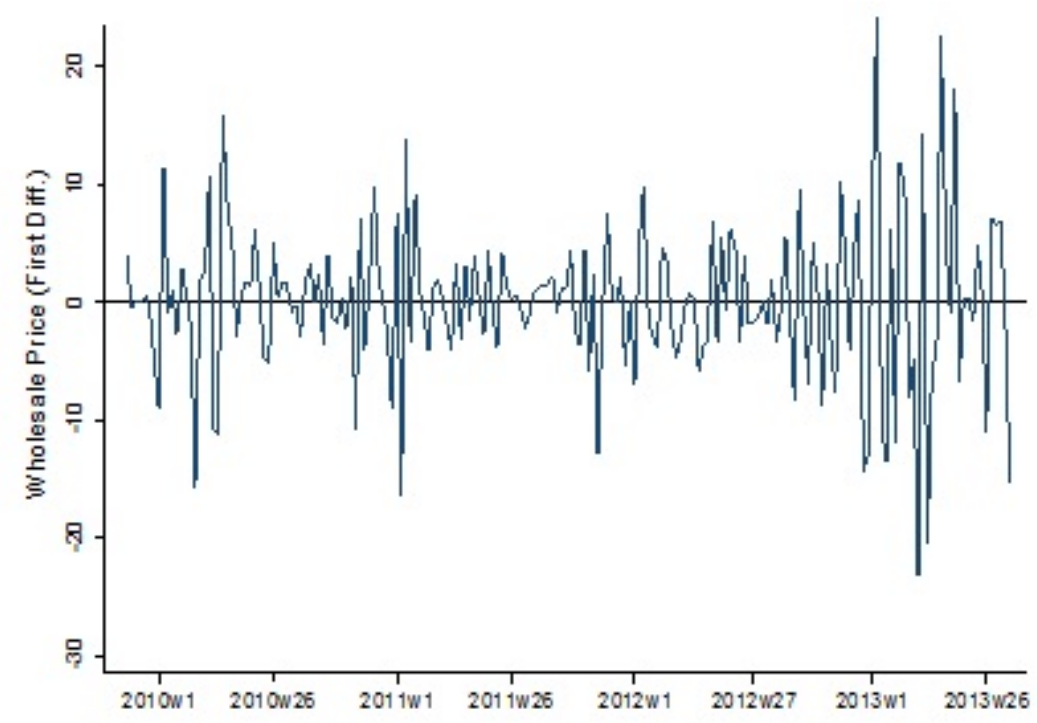

Following the same empirical strategy as in the $\Delta W P_{t}$ model, for the analysis of the feed-in tariff costs the estimation is performed in differences with a lag dependent variable $\Delta F I T C_{t-1}$. Eq. (2) represents the change in the cost of the FIT per unit of electricity consumption $\left(\Delta F I T C_{t}\right)$ capturing the effect from change in the composition of electricity production by different sources (wind, solar, small hydro, other renewable, and cogeneration) covered through the FIT system $\left(\Delta M i x_{t}\right)$. Unlike in the case of $\Delta W P_{t}$, the $\Delta F I T C_{t}$ variance (despite its volatility which is high but not increasing, see Figure 5) does not follow an ARCH process. However, the $\Delta F I T C_{t}$ series does follows a moving-average process of first order, for this reason we introduce $\epsilon_{2 t-1}$ component.

To obtain the weekly $\Delta F I T C_{t}$ the following procedure is used. First, in the same line as Burgos-Payn et al. (2013), from the CNE statistics ${ }^{3}$ on FIT payments we take the yearly amount of Euros by technology devoted to the incentives of firms producing electricity from RES and COG. Second, the yearly amount of Euros per technology is weighted by the daily proportion of their yearly production (Prod-day / Prod-year) and added to obtain the daily cost of FIT. Third, to account for volume differences, we compute the cost of the FITs per unit of electricity consumption (load). Finally, we compute the weekly average.

\footnotetext{
$\overline{3}$ "Informacion Estadistica sobre las Ventas de Energia del Regimen Especial", available at www.cne.es
} 
Figure 5: Feed-in Tariff Cost (first differences)

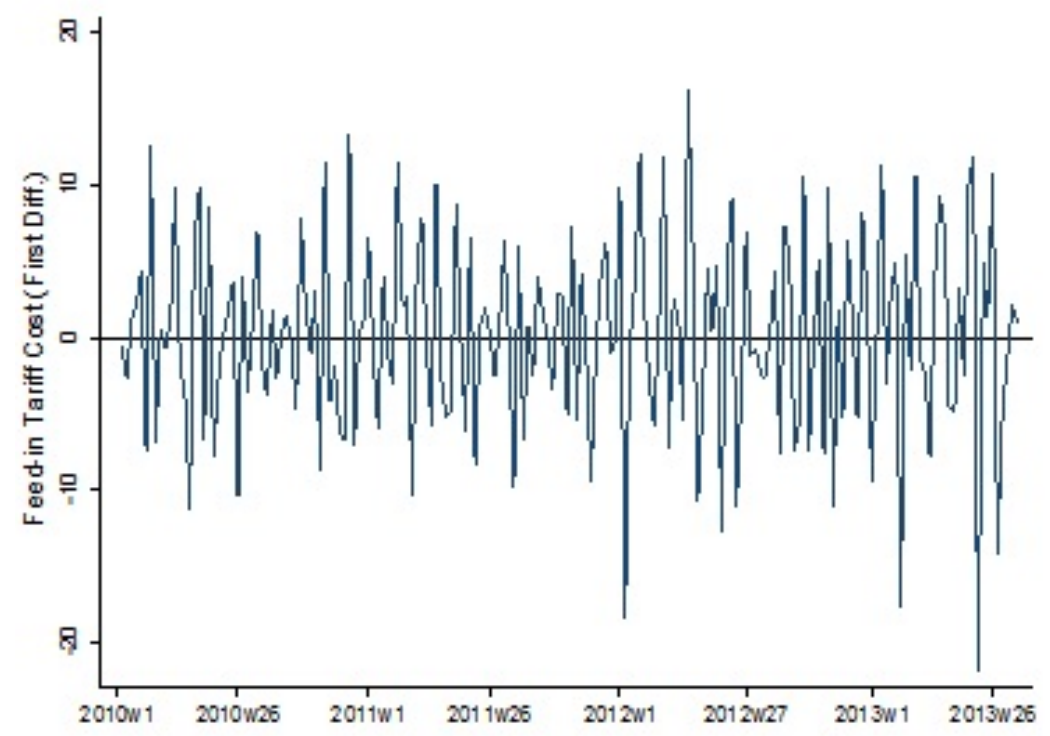

The period covered for the estimation of the wholesale price and the feed-in tariff cost equations is from November 2009 to July 2013 (195 weeks). The selection of this period is motivated by regulatory stability and data reliability: up to October 2009 the distribution companies were in charge of handling the FIT payments to the Special Regime (SR) producers. Since November 2009 the CNMC is responsible for the FIT payments, providing public and reliable information on those payments ${ }^{4}$.

The analysis of effect that the FIT regulation has over electricity retail price $\left(R P_{t}\right)$ is performed through the estimation of Eq. (3), which quantifies the retail price change as a function of changes from both the cost of the incentive to electricity generation under the FIT and the wholesale price of electricity. To capture dynamic effects an autoregressive term $\left(R P_{t-1}\right)$ was introduced in the model. $\widehat{W P}_{t}$ is the estimated weekly average of the (day-ahead) spot market price capturing the effect from the composition of electricity production by energy sources (Eq. (1)). $\widehat{F I T C}_{t}$ is the estimated FIT cost per unit of electricity consumption capturing the effect from the electricity production by RES and COG (Eq. (2)).

According to the Spanish price design, the industrial retal price ( $R P$, excluding taxes) is the result of adding the Access Tariff $(A T)$, the Net Retail Margins $(N R M)$ and the Wholesale Cost $(W C)$. The AT data comes from Spanish national regulatory agency the National Commission of Markets and Communications (by its acronym in Spanish CNMC, previously

\footnotetext{
${ }^{4}$ In practice it is possible to obtain the payments by both as a direct tariff or as a premium over the market price, here we use the total resources (the FITC) because captures the overall cost of the policy.
} 
named National Commission of Energy, CNE) reports on monitoring the retail market ${ }^{5}$. The NRM, obtained from the same source, were computed quarterly by the CNMC based on two forward purchasing strategies by retailers (see (CNE, 2013)). We follow the same methodology for one forward purchasing strategy to approach their WC on rolling basis; using weekly, monthly and quarterly contracts (see Appendix for additional details on the $R P$ proxy) ${ }^{6}$. In order to develop comprehensive empirical estimations weekly data for the period between April 2010 and June 2012 is used (116 weeks). The selection of this period is motivated by data availability. Figure 6 shows the industrial retail price in first differences.

Figure 6: Retail Price (first differences)

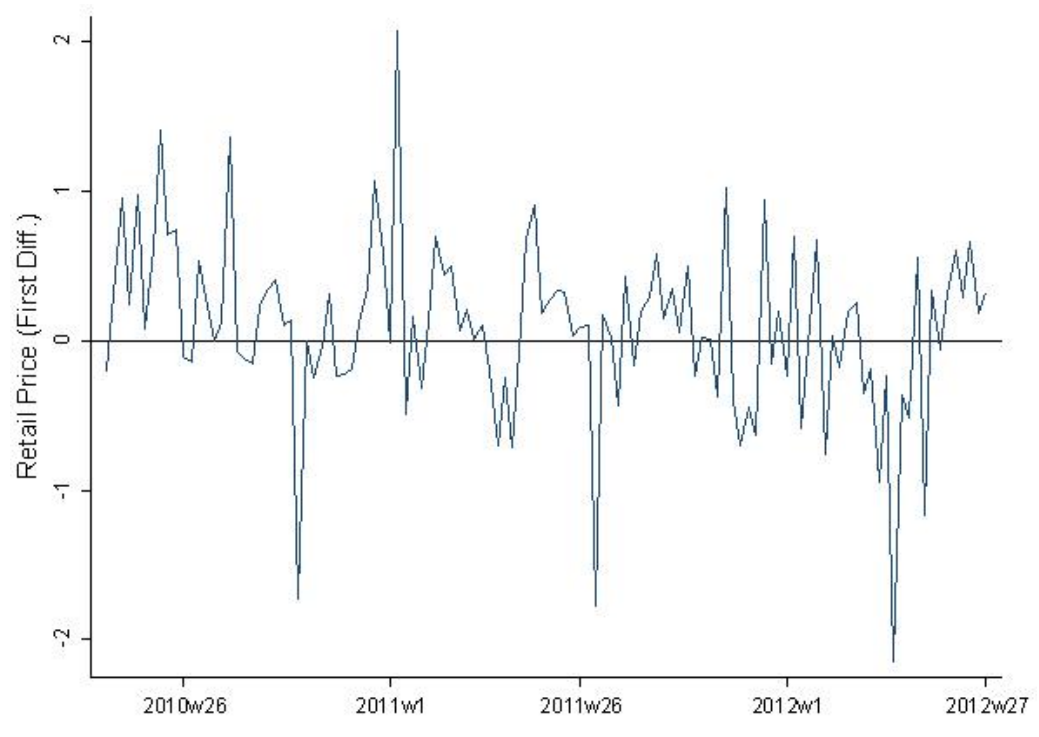

Finally, it is importan to highlight that in all three equations the seasonality is controlled using fourth set of dummies variables: yearly $\left(\Delta Y_{t}\right)$, quarterly $\left(\Delta Q_{t}\right)$, monthly $\left(\Delta M_{t}\right)$, and weekly $\left(\Delta W_{t}\right)$ dummies. Table 1 shows the summary statistics of the data used. While all prices and cost (RP, WP and FITC) are measured in $€ / \mathrm{MWh}$, all electricity volumes are measured in GWh.

\footnotetext{
5 "Informe de Supervision del Mercado Minorista de Electricidad Julio 2011 - Junio 2012", ((CNE, 2013)). More precisely we used the CNMC access tariff for the average industrial consumer according to the RD $110 / 2007$ consumers classification.

${ }^{6}$ As pointed out in CNE (2013) and Ofgem (2008), firms can employ a range of hedging strategies and these may change over time. For practical purposes we used one of the two purchasing strategies employed by the CNMC for industrial consumers. In the dynamic strategy we used, the supplier buys during remaining time before the rolling period ends to cover the delivery, while in the other strategy the portfolio length is uniformly distributed through the products within the rolling period. Given that our model is in first differences and capture long-term effects, results are expected to be consistent to the use of different strategies.
} 
Table 1: Summary Statistics

\begin{tabular}{lccccc}
\hline \hline \multicolumn{1}{c}{ Variable } & Obs & Mean & Std. Dev. & Min & Max \\
\hline RP Industrial & 116 & 79.8259 & 3.2661 & 69.7313 & 84.1047 \\
WP & 195 & 43.298 & 10.4807 & 3.25 & 63.6914 \\
FITC & 195 & 47.8293 & 10.1541 & 28.0443 & 82.564 \\
Load & 195 & 28.7619 & 2.0537 & 23.9702 & 34.1131 \\
SR & 195 & 11.2848 & 2.1422 & 7.0179 & 17.75 \\
RES & 195 & 7.5922 & 2.0167 & 3.994 & 13.6012 \\
COG & 195 & 3.693 & 0.2784 & 2.6667 & 4.2143 \\
Wind & 195 & 5.3534 & 1.969 & 1.9167 & 11.6012 \\
Solar & 195 & 1.073 & 0.5014 & 0.2396 & 2.4762 \\
Hydro S & 195 & 0.6869 & 0.2516 & 0.2083 & 1.1786 \\
Hydro B & 195 & 3.4741 & 1.677 & 1.3571 & 8.6905 \\
Hydro T & 195 & 4.161 & 1.8973 & 1.6667 & 9.7738 \\
Other Renew & 195 & 0.4788 & 0.0931 & 0.3155 & 0.6667 \\
Nuclear & 195 & 6.7936 & 0.8035 & 4.0833 & 7.8869 \\
Coal & 195 & 4.3477 & 2.1268 & 0.3036 & 9.1607 \\
Comb Cycle & 195 & 5.4349 & 2.2302 & 1.3452 & 11.5238 \\
\hline
\end{tabular}

Once described the models and data used, we present the stationarity analysis of the series. We performed two test, first, the augmented Dickey-Fuller (ADF) test (Dickey and Fuller, 1979) under the null hypothesis of a unit root and, second, the Kwiatkowski-Phillips-SchmidtShin (KPSS) tests (Kwiatkowski et al., 1992) under the null hypothesis of stationarity. While results of ADF test (see Table 2) in levels indicate that, we cannot reject the null hypothesis of a unit root in WP, FITC or RP at any reasonable level of significance, results in first differences indicate that we can reject the null hypothesis of a unit root for all three series. In addition, KPSS results in levels indicate that we can reject the null hypothesis of stationarity in WP, FITC and RP in any case, and in first difference that we cannot reject the null hypothesis of stationarity at $1 \%$ level of significance. Both tests confirm that WP, FITC and RP weekly series are stationary in first differences so we estimate the models in first differences ${ }^{7}$.

Table 2: Augmented Dickey-Fuller and Kwiatkowski-Phillips-Schmidt-Shin test

\begin{tabular}{lcccc}
\hline \hline & \multicolumn{2}{c}{ ADF test } & \multicolumn{2}{c}{ KPSS test } \\
\hline & Levels & First differences & Levels & First differences \\
\hline Wholesale Price $(W P)$ & -3.061 & $-9.005^{* * *}$ & $1.060^{* * *}$ & 0.038 \\
Feed-in Tariff Cost $(F I T C)$ & -3.247 & $-9.751^{* * *}$ & $3.090^{* * *}$ & 0.054 \\
Retail Price $(R P)$ & -2.606 & $-4.695^{* * *}$ & $2.350^{* * *}$ & 0.541 \\
\hline
\end{tabular}

Note: Test results are statistics. Lag length is determined by the Modified Akaike Information Criterion. The trend was not significant in any case, hence, it was excluded. ADF null hypothesis of unit root. KPSS null hypothesis of stationarity. ${ }^{* * *}$ Significant at $1 \%$.

\footnotetext{
${ }^{7}$ Furthermore, estimations results with absolute value of AR coefficients lower than one confirms the stationarity of the series.
} 


\section{Results}

Given that the effects from FIT regulation come through the proportion and type of renewable sources in the energy mix, three set of estimations are perform for each equation with different aggregations of the electricity mix. While in Set 1 a single variable captures the electricity generated under the FIT system (SR), in Set 2 we distinguish between renewable (RES) and cogeneration (COG) under the FIT system, and in Set 3 the renewable sources are disaggregated in Wind, Solar, Small Hydro, and Other Renewable. In addition to electricity generated under the FIT system, other main technologies of the energy mix are introduced in the WP equation (Combined Cycle, Nuclear, Coal and Hydro ${ }^{8}$ ). Table 3 and Table 4 shows the results of the three maximum likelihood estimations with robust standard errors for the $\Delta W P_{t}$ (Eq. (1)) and $\Delta F I T C_{t}$ (Eq. (2)), respectively. We first present results from all estimations with the short-run analysis. This is followed by a summary and comparison between short-run and long-run implications.

In general, results from the WP equation are consistent with those of previous studies; the introduction of RES exerts a downward pressure on the wholesale price of electricity. At an aggregated level (Set 1), results indicates that in the short-run one additional GWh of electricity generated under the FIT system (SR) decrease the WP (Table 3) in the magnitude of $1.13 € / \mathrm{MWh}(-2.61 \%)$ and increase the FITC (Table 4) on $2.08 € / \mathrm{MWh}(4.35 \%)$. When separating renewable from cogeneration (Set 2) results for renewable are very similar to the aggregated FIT system, showing that an additional GWh of renewable production decrease the WP in $1.09 € /$ MWh $(-2.53 \%)$ and an increase in $2.07 € /$ MWh of the FITC (4.33\%).

The renewable sources are disaggregated in the last group of estimations (Set 3). Results shows that one additional GWh of wind production decrease the WP in the magnitude of $1.11 € / \mathrm{MWh}(-2.56 \%)$ and increase the FITC in $2.22 € / \mathrm{MWh}(4.66 \%)$. In the case of solar production, an additional GWh decrease the WP $2.51 € / \mathrm{MWh}(-5.80 \%)$ and increase 9.94 $€ /$ MWh the FITC (20.79\%). Finally, cogeneration results shows that one additional GWh of its production decrease the WP around $2.64 € / \mathrm{MWh}(-6.12 \%)$ and increases $4.62 € / \mathrm{MWh}$ the FITC (9.67\%).

\footnotetext{
${ }^{8}$ Given that small hydro generation is part of the RES under the FIT system, to avoid double imputation of small hydro in the mix, only big hydro generation was introduced as additional control in the first two estimations of the WP. Furthermore, to avoid multicolineality problems coming from the high correlation between small and big hydro, total hydro was introduce in the third estimation of the WP.
} 
Table 3: Wholesale Price

\begin{tabular}{|c|c|c|c|}
\hline$\Delta W P_{t}$ & (1) & $(2)$ & (3) \\
\hline$\Delta W P_{t-1}$ & $\begin{array}{c}-0.287^{* * *} \\
(0.044)\end{array}$ & $\begin{array}{c}-0.284^{* * *} \\
(0.044)\end{array}$ & $\begin{array}{c}-0.238^{* * *} \\
(0.047)\end{array}$ \\
\hline$\Delta$ Load & $\begin{array}{c}0.814^{* * *} \\
(0.219)\end{array}$ & $\begin{array}{c}0.821^{* * *} \\
(0.203)\end{array}$ & $\begin{array}{c}0.844^{* * *} \\
(0.264)\end{array}$ \\
\hline$\Delta S R$ & $\begin{array}{c}-1.128^{* * *} \\
(0.179)\end{array}$ & & \\
\hline$\triangle R E S$ & & $\begin{array}{c}-1.095^{* * *} \\
(0.167)\end{array}$ & \\
\hline$\triangle C O G$ & & $\begin{array}{c}-2.330^{* *} \\
(0.907)\end{array}$ & $\begin{array}{c}-2.648^{* * *} \\
(1.002)\end{array}$ \\
\hline$\Delta W i n d$ & & & $\begin{array}{c}-1.109^{* * *} \\
(0.210)\end{array}$ \\
\hline$\Delta$ Solar & & & $\begin{array}{c}-2.512^{* * *} \\
(0.758)\end{array}$ \\
\hline$\Delta$ OtherRenew & & & $\begin{array}{c}7.312 \\
(5.361)\end{array}$ \\
\hline$\Delta$ CombCycle & $\begin{array}{c}0.322 \\
(0.210)\end{array}$ & $\begin{array}{l}0.365^{*} \\
(0.200)\end{array}$ & $\begin{array}{c}0.280 \\
(0.258)\end{array}$ \\
\hline$\Delta$ Nuclear & $\begin{array}{l}-0.248 \\
(0.270)\end{array}$ & $\begin{array}{l}-0.267 \\
(0.279)\end{array}$ & $\begin{array}{l}-0.426 \\
(0.370)\end{array}$ \\
\hline$\Delta$ Coal & $\begin{array}{c}0.951^{* * *} \\
(0.201)\end{array}$ & $\begin{array}{c}0.953^{* * *} \\
(0.193)\end{array}$ & $\begin{array}{c}0.939 * * * \\
(0.243)\end{array}$ \\
\hline$\Delta H y d r o B$ & $\begin{array}{c}-3.169^{* * *} \\
(0.240)\end{array}$ & $\begin{array}{c}-3.180^{* * *} \\
(0.235)\end{array}$ & \\
\hline$\Delta H y d r o T$ & & & $\begin{array}{c}-2.836^{* * *} \\
(0.242)\end{array}$ \\
\hline Constant & $\begin{array}{c}0.145 \\
(0.0945)\end{array}$ & $\begin{array}{c}0.134 \\
(0.0900)\end{array}$ & $\begin{array}{l}0.0379 \\
(0.102)\end{array}$ \\
\hline$\delta_{1}$ & $\begin{array}{c}0.870^{* * *} \\
(0.367)\end{array}$ & $\begin{array}{c}0.752^{* * *} \\
(0.367)\end{array}$ & $\begin{array}{c}0.728^{* * *} \\
(0.339)\end{array}$ \\
\hline$\delta_{0}$ & $\begin{array}{l}1.200^{* *} \\
(0.470)\end{array}$ & $\begin{array}{c}1.083^{* *} \\
(0.457)\end{array}$ & $\begin{array}{c}0.949 * * * \\
(0.360)\end{array}$ \\
\hline \multicolumn{4}{|l|}{ Seasonality } \\
\hline Year & $\mathrm{Y}$ & $\mathrm{Y}$ & $\mathrm{Y}$ \\
\hline Quarter & Y & $\mathrm{Y}$ & $\mathrm{Y}$ \\
\hline Month & $\mathrm{Y}$ & $\mathrm{Y}$ & $\mathrm{Y}$ \\
\hline Week & $\mathrm{N}$ & $\mathrm{N}$ & $\mathrm{N}$ \\
\hline Observations & 194 & 194 & 194 \\
\hline$R S D$ of residuals & 46.620 & 43.033 & 25.049 \\
\hline
\end{tabular}

Note: Robust standard errors are in parentheses. ${ }^{*}$ Significant at $10 \%, * *$ Significant at $5 \%, * * *$ Significant at $1 \%$. The 51 weekly dummies were excluded from the wholesale price seasonality to allow the optimization of the ARCH process. 
Table 4: Feed-in Tariff Cost

\begin{tabular}{|c|c|c|c|}
\hline$\Delta F I T C_{t}$ & (1) & $(2)$ & (3) \\
\hline$\Delta F I T C_{t-1}$ & $\begin{array}{c}-0.231^{* *} \\
(0.102)\end{array}$ & $\begin{array}{c}-0.256^{* *} \\
(0.0995)\end{array}$ & $\begin{array}{c}-0.344^{* * *} \\
(0.104)\end{array}$ \\
\hline$\Delta S R$ & $\begin{array}{c}2.081^{* * *} \\
(0.203)\end{array}$ & & \\
\hline$\triangle R E S$ & & $\begin{array}{c}2.072^{* * *} \\
(0.198)\end{array}$ & \\
\hline$\triangle C O G$ & & $\begin{array}{c}6.034^{* *} \\
(2.974)\end{array}$ & $\begin{array}{l}4.625^{*} \\
(2.535)\end{array}$ \\
\hline$\Delta W$ ind & & & $\begin{array}{c}2.227^{* * *} \\
(0.189)\end{array}$ \\
\hline$\Delta$ Solar & & & $\begin{array}{c}9.944^{* * *} \\
(1.331)\end{array}$ \\
\hline$\Delta H y d r o S$ & & & $\begin{array}{c}1.671 \\
(1.908)\end{array}$ \\
\hline$\Delta$ OtherRenew & & & $\begin{array}{l}-9.837 \\
(8.006)\end{array}$ \\
\hline Constant & $\begin{array}{l}0.0816 \\
(0.057)\end{array}$ & $\begin{array}{l}0.0764 \\
(0.062)\end{array}$ & $\begin{array}{c}0.0612^{* * *} \\
(0.016)\end{array}$ \\
\hline$\epsilon_{t-1}$ & $\begin{array}{c}2.170^{* * *} \\
(0.367)\end{array}$ & $\begin{array}{c}2.203^{* * *} \\
(0.367)\end{array}$ & $\begin{array}{c}2.168^{* * *} \\
(0.339)\end{array}$ \\
\hline \multicolumn{4}{|l|}{ Seasonality } \\
\hline Year & $\mathrm{Y}$ & $\mathrm{Y}$ & $\mathrm{Y}$ \\
\hline Quarter & $\mathrm{Y}$ & $\mathrm{Y}$ & $\mathrm{Y}$ \\
\hline Month & $\mathrm{Y}$ & $\mathrm{Y}$ & $\mathrm{Y}$ \\
\hline Week & $\mathrm{Y}$ & $\mathrm{Y}$ & $\mathrm{Y}$ \\
\hline Observations & 194 & 194 & 194 \\
\hline SD of residuals & 46.620 & 43.033 & 25.049 \\
\hline
\end{tabular}

Note: Robust standard errors are in parentheses. * Significant at $10 \%, * *$ Significant at $5 \%, * * *$ Significant at $1 \%$.

The other coefficients of the remaining explanatory variables are very similar across specifications. Besides, as measure of the statistical estimates reliability Table 3 and Table 4 shows the relative standard deviation (RSD) and the standard deviation (SD) of residuals, respectively. Decreasing value of both indicators with higher desaggregations of the electricity mix (from Set 1 to Set 3), confirms the adequacy and relevance of technology consideration in the context of this study. Furthermore, the models goodness of fit are very high as can be seen in Figure 7 and Figure 8 showing the observed and predicted values from Eq.(1) and Eq.(2), respectively. As a robustness check, when re-estimating the WP model including the gas price as an additional control, the effect is positive but not significant, and the rest of estimated coefficients remain unchanged. This not significant result might comes from the fact that gas price effect it is captured, at least partially, by the combined cycle contribution into the electricity mix. 
Figure 7: Goodness of fit Eq. (1)
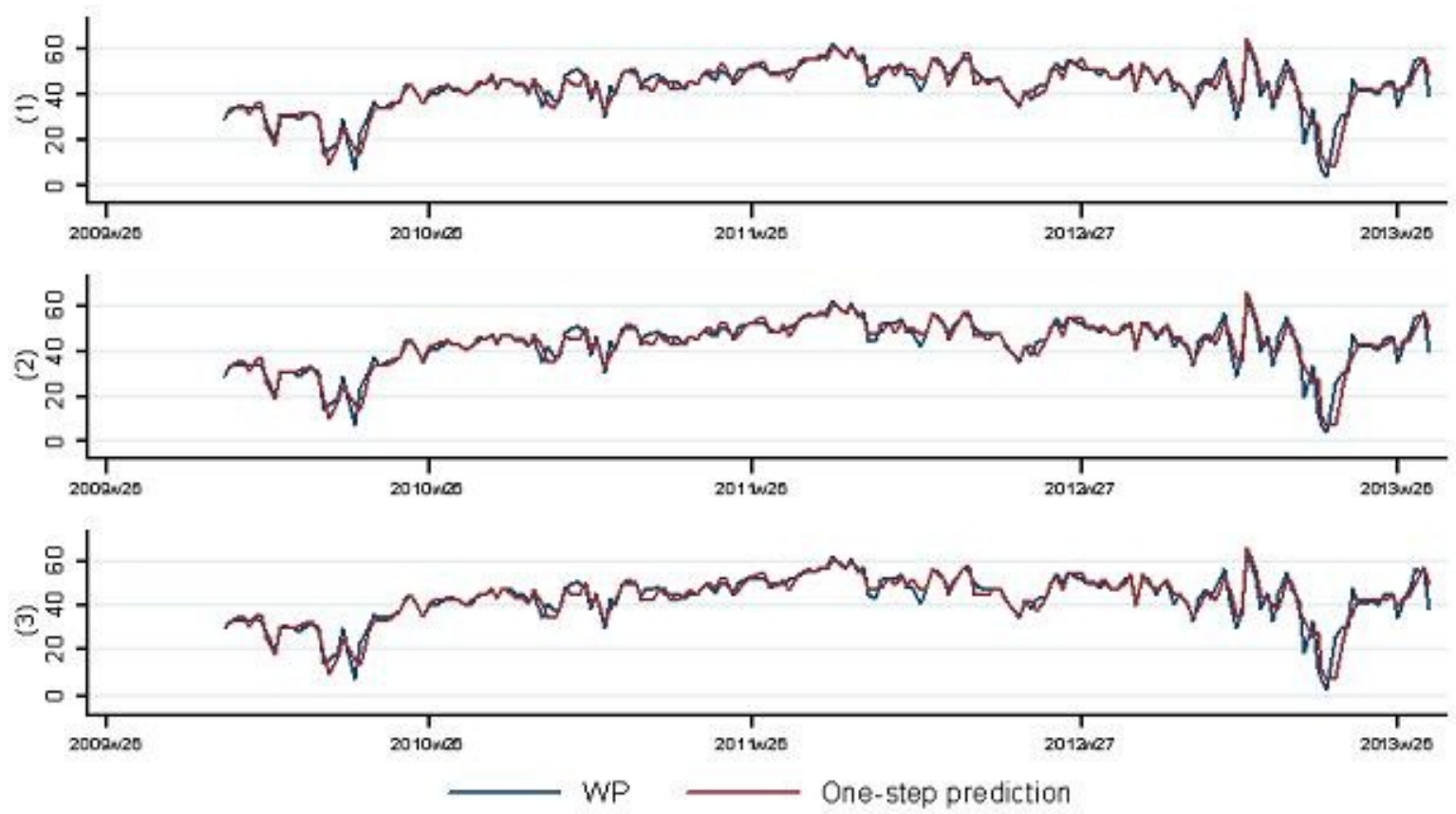

Figure 8: Goodness of fit Eq. (2)
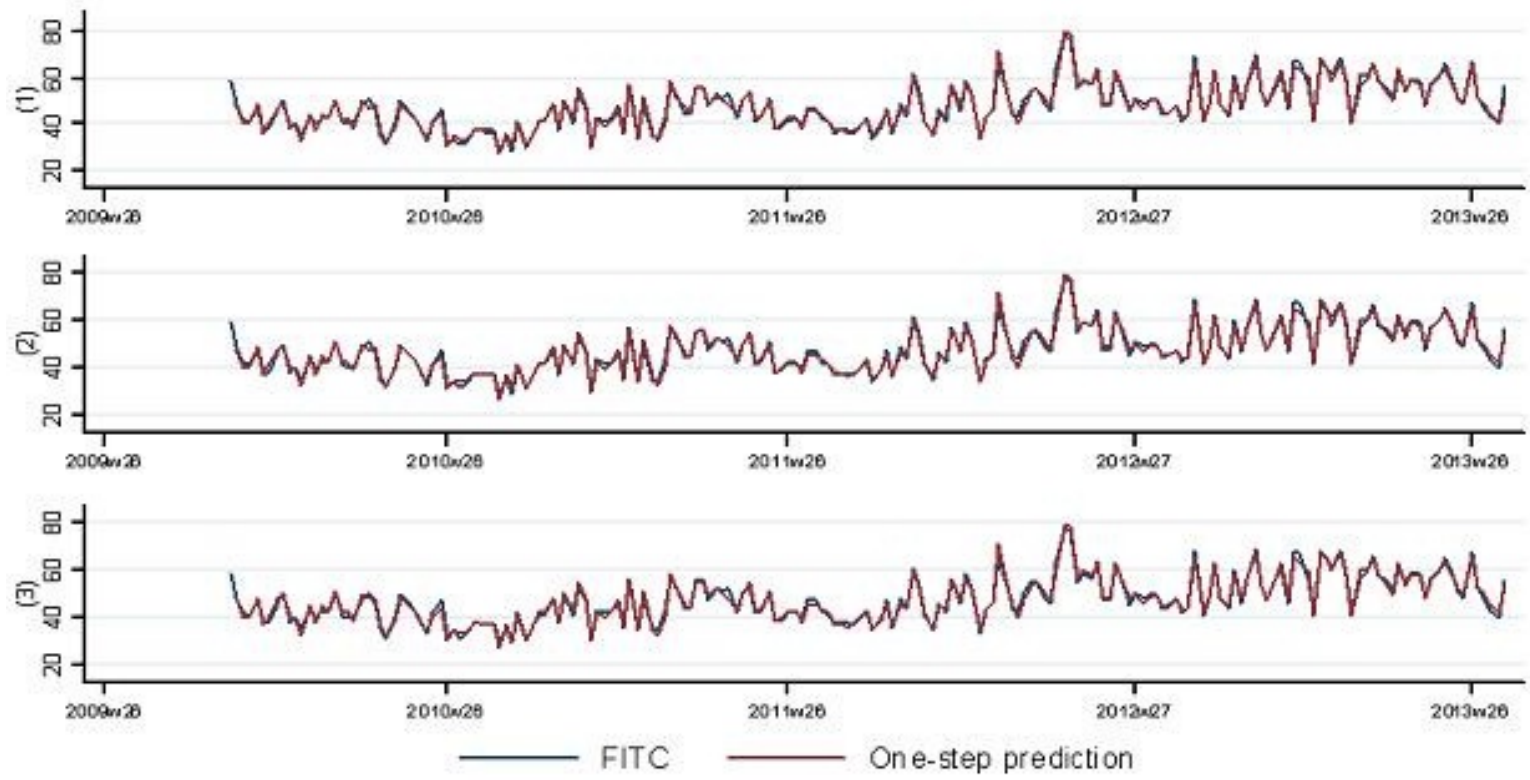
Once considered the effect of electricity produced under the FIT regulation over the WP and FITC, the overall impact of the FIT regulation on retail price will ultimately depend on the relative intensities of the effects exerted through WP and FITC. This analysis is performed through the estimation of the Eq. (3) for industrial consumers using the predicted values of $\mathrm{WP}$ and FITC resulting from previous estimations.

Given that $\widehat{W P}_{t}$ and $\widehat{F I T C}_{t}$ are both function of the energy mix some worries might arise on effect over the retail price equation from the potentially high correlation between them. Nonetheless, the correlation between the two estimated variables is -0.1318 for results in Set1, -0.1321 in the Set2, and -0.1507 in the Set3. Results from estimations of Eq. (3) are presented in Table 5.

Table 5: Retail Price Industrial

\begin{tabular}{lccc}
\hline \hline$\Delta R P_{t}$ & $(1)$ & $(2)$ & $(3)$ \\
\hline & & & \\
$\Delta R P_{t-1}$ & $0.154^{* *}$ & $0.155^{* *}$ & $0.178^{* *}$ \\
& $(0.073)$ & $(0.072)$ & $(0.076)$ \\
$\Delta \widehat{W P}_{t}$ & $0.034^{* * *}$ & $0.030^{* * *}$ & $0.0367^{* * *}$ \\
& $(0.011)$ & $(0.011)$ & $(0.011)$ \\
$\widehat{F I T C}_{t}$ & $0.034^{* * *}$ & $0.028^{* * *}$ & $0.037^{* * *}$ \\
& $(0.009)$ & $(0.009)$ & $(0.009)$ \\
Constant & 0.059 & 0.060 & 0.057 \\
& $(0.037)$ & $(0.037)$ & $(0.037)$ \\
\hline Seasonality & & & \\
Year & $\mathrm{Y}$ & $\mathrm{Y}$ & $\mathrm{Y}$ \\
Quarter & $\mathrm{Y}$ & $\mathrm{Y}$ & $\mathrm{Y}$ \\
Month & $\mathrm{Y}$ & $\mathrm{Y}$ & $\mathrm{Y}$ \\
Week & $\mathrm{Y}$ & $\mathrm{Y}$ & $\mathrm{Y}$ \\
Observations & 116 & 116 & 116 \\
SD of residuals & 0.337 & 0.335 & 0.330 \\
\hline Note: Robust standard errors are in parentheses. ${ }^{*}$ Signif-
\end{tabular}

icant at $10 \%, * *$ Significant at $5 \%, * * *$ Significant at $1 \%$.

In general, all estimations indicate that the short-run effects from changes in WP and FITC on the RP change are small and similar. At an aggregated level (Set 1), results shows that an increase of $1 € / \mathrm{MWh}$ in the WP and the FITC leads to increase the RP in $0.0337 € / \mathrm{MWh}$ and $0.0344 € / M W h$ respectively. Combining the estimated effects from Eq.(1) and Eq.(2) over the WP and the FITC with these retail price effects ${ }^{9}$ we obtain that, from one additional GWh of production under the FIT system (9\% more) the RP increase in $0.042 \%$. When separating renewable from cogeneration (Set 2), results are very similar showing that increase of $1 € / \mathrm{MWh}$ in the WP and the FITC leads to increase the RP in $0.0306 € / \mathrm{MWh}$ and 0.0283

\footnotetext{
${ }^{9}$ The final short-run effect on the RP from one additional GWh of production is calculated as follows: $\alpha_{2} *\left[\beta_{3} / \overline{W P}\right]+\alpha_{3} *\left[\lambda_{2} / \overline{F I T C}\right]$
} 
$€ / M W h$ respectively. Hence, an extra GWh of renewable production (13.2\% more) increase the RP in the short-run in $0.031 \%$.

Finally, when renewable sources are disaggregated (Set 3), results shows that an increase of 1 $€ / \mathrm{MWh}$ in the WP and the FITC increases the RP in $0.0366 € / \mathrm{MWh}$ and $0.0373 € / \mathrm{MWh}$ respectively. Therefore, short-run one additional $\mathrm{GWh}$ in the case of wind (18.7\% more) increase the RP in $0.053 \%$, and in the case of solar (93.2\% more) increase the RP in $0.349 \%$.

As in previous models, using the standard deviation (SD) of residuals (see Table 4) as measure of the statistical estimates reliability, we observe that is has decreasing value with higher disaggregation of the electricity mix (from Set 1 to Set 3). Besides, the retail price model goodness of fit is very high as can be seen in Figure 9 showing the observed and predicted values from the retail price equation.

Figure 9: Goodness of fit Eq. (3)
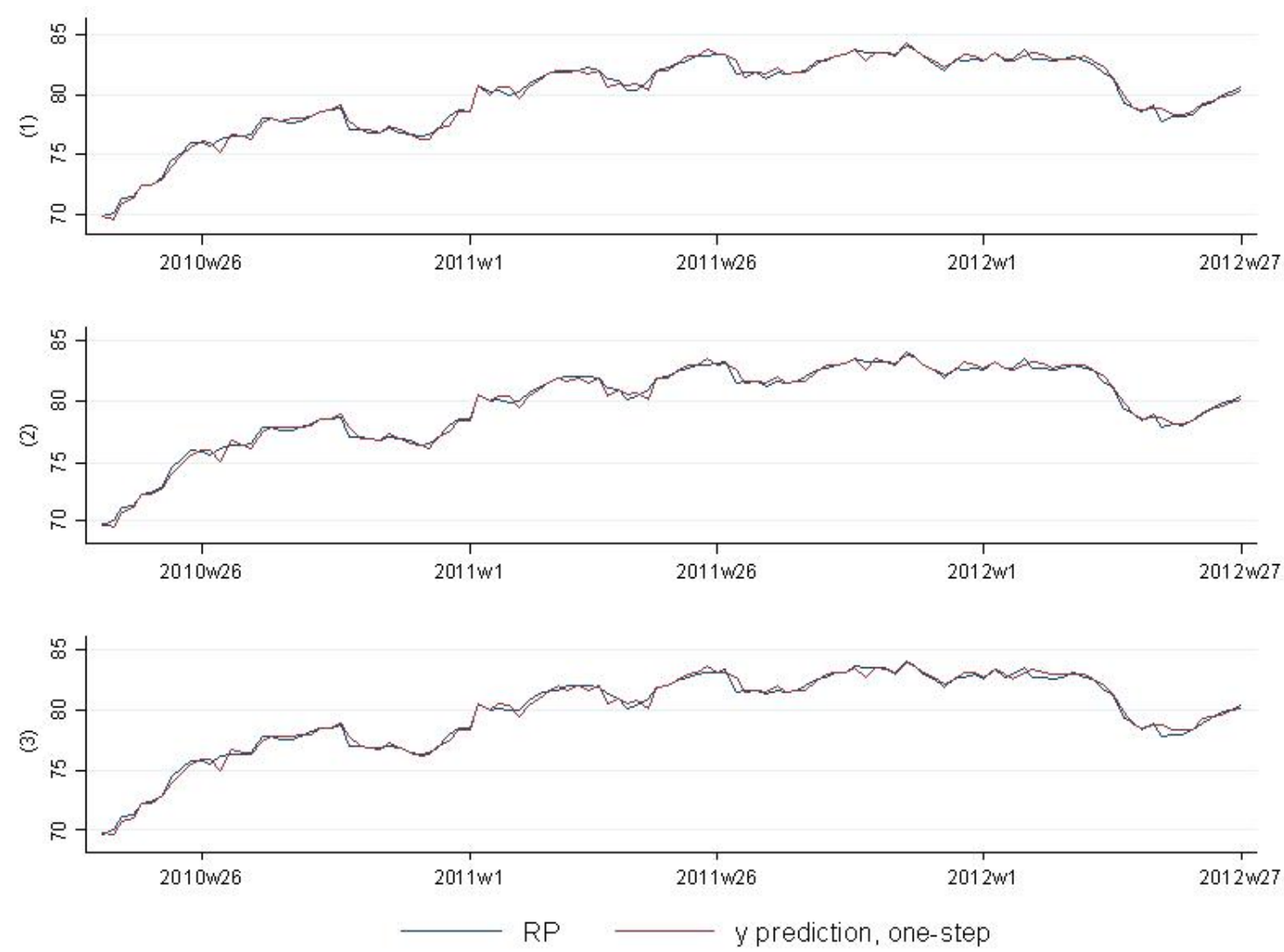

Estimated coefficients from lagged dependent variables were used compute the long-run effects ${ }^{10}$. A summary of the short-run and long-run effects FIT regulation in the average WP,

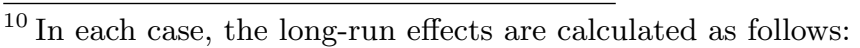


FITC and RP are presented in Table 6 . In the case of the long-run effects it is interesting to highlight that they decrease for WP and FITC with respect to those in the short-run, the effect of one additional GWh of production under the FIT system over the WP and the FITC is stronger in the short than in the long-run ( $\beta_{1}$ and $\lambda_{1}$ are negative). The opposite happened in for the RP, in the long-run the effect of additional production under the FIT system increase with respect to those observed in the short-run ( $\alpha_{1}$ is positive).

Table 6: Effects from one additional GWh of production

\begin{tabular}{|c|c|c|c|c|}
\hline Short-Run & SR & RES & Wind & Solar \\
\hline WP & $-2.61 \%$ & $-2.53 \%$ & $-2.56 \%$ & $-5.80 \%$ \\
\hline FITC & $4.35 \%$ & $4.33 \%$ & $4.66 \%$ & $20.79 \%$ \\
\hline $\mathrm{RP}$ & $0.042 \%$ & $0.031 \%$ & $0.053 \%$ & $0.349 \%$ \\
\hline Long-Run & $\mathrm{SR}$ & RES & Wind & Solar \\
\hline WP & $-2.02 \%$ & $-1.97 \%$ & $-2.07 \%$ & $-4.69 \%$ \\
\hline FITC & $3.54 \%$ & $3.45 \%$ & $3.47 \%$ & $15.47 \%$ \\
\hline $\mathrm{RP}$ & $0.06 \%$ & $0.04 \%$ & $0.07 \%$ & $0.49 \%$ \\
\hline
\end{tabular}

\section{$5 \quad$ Discussion and policy implications}

In this study we analyzed the effects that feed-in tariff regulation has on Spanish electricity retail prices. This analysis is performed by quantifying the relative effects of the cost of the incentives for electricity generation under the FIT and the electricity wholesale price on the industrial retail price.

At an aggregated level, results confirms that an increase of about $9 \%$ of the total production under the FIT system leads to a decrease of $2.61 \%$ of the WP and an increase of $4.35 \%$ of the FIT cost (FITC). Regarding final industrial consumers, the previous mentioned effects over WP and FITC are translated into a $0.042 \%$ increase of the average retail price. These results, although illustrative, must be carefully interpreted because do not take into account the effect from different technologies.

One interesting finding from this study is that the effects from one additional GWh of solar production on the WP and on the FITC is stronger than the effects from wind. In the case of the WP this seems to be the confirmation of the differentiated effect from the fact that

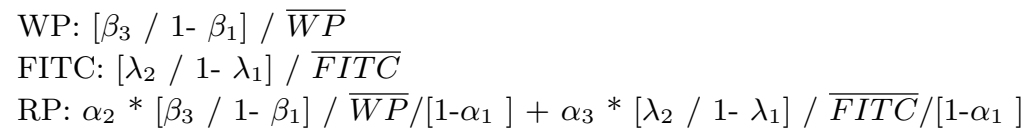


both technologies make different contributions of electricity to the system during the day, characterized by different demand profiles. Even though solar contribution to the energy mix is relatively small (less than $5 \%$ in average), given that it is available during peak hours, the downward pressure that exerts over the WP is stronger than the one from wind with a higher penetration (around 20\%) but relatively stronger during off-peak hours. Nevertheless, this would need a further evaluation using hourly data. In the case of FITC the stronger effect from solar it is much more straightforward, it is capturing the extremely high FIT incentive in terms of $€ / M W h$ devoted to this technology.

Regarding the final impact on industrial retail price from previous mentioned result, the effect of one additional GWh solar production is 6.6 higher that the effect coming from wind in the short-run and 7.6 higher in the long-run. When looking at these effects, it is important to highlight that one additional GWh of solar would imply increasing 93.2\% its average generation while in the case of wind it would represent only an $18.7 \%$. To place these results into perspective, we compute the effects from a $10 \%$ increase of the average production from both technologies on the average retail price. Result indicates that a $10 \%$ increase of solar generation leads to an increase in the retail price which it is actually only 1.5 higher that the effect coming from $10 \%$ more wind.

With respect to the small magnitude of the retail price effects, it has been recently pointed out by the European Commission that, in an open and competitive retail market the pricing signals should provide a strong link between the retail and wholesale market, and the final consumers would then be able to adapt their economic decisions in line with the supply and demand fundamentals. These conditions are rarely met in todays retail markets in the EU (EC, 2014). From our analysis we conclude that there is not a strong link between the retail and wholesale market for Spanish industrial consumers. This is possible the consequence of a variety of factors and barriers that are limiting the retail market competition, and hence, preventing final consumers from facing the potential welfare effects resulting of both, the competitive wholesale market in which the feed-in tariff regulation it is exerting an price suppressing effect, and the cost of financing this renewable promotion mechanism.

From the above discussion it is apparent that, first, such regulations has implications above and beyond the specific goals they were designed to achieve. Those responsible for introducing regulations therefore need to be painstaking in their efforts when evaluating these implications so as to anticipate their potentially negative effects. Second, measures to improve the retail market competition are need. To split retails from vertically related operator might help in this direction, as well as, the deployment of smart meters with bidirectional information technology and the equipment handled by retailers -instead of distributors as in the current system. 


\section{References}

Burgos-Payan, M., J. M. Roldan-Fernandez, A. L. Trigo-Garcia, J. M. Bermudez-Rios, and J. M. Riquelme-Santos (2013). Costs and benefits of the renewable production of electricity in spain. Energy Policy 56, 259-270.

CEER (2013). Status review of renewable and energy efficiency support schemes in europe.

Ciarreta, A., M. P. Espinosa, and C. Pizarro-Irizar (2014). Is green energy expensive? empirical evidence from the spanish electricity market. Energy Policy 69(0), $205-215$.

CNE (2013). Informe de supervision del mercado minorista de electricidad julio 2011 - junio 2012. Technical report.

Del Rio, P. and M. A. Gual (2007). An integrated assessment of the feed-in tariff system in spain. Energy Policy 35(2), 994-1012.

Dickey, D. A. and W. A. Fuller (1979). Distribution of the estimators for autoregressive time series with a unit root. Journal of the American Statistical Association 74 (366a), 427-431.

Frondel, M., N. Ritter, C. M. Schmidt, and C. Vance (2010). Economic impacts from the promotion of renewable energy technologies: The german experience. Energy Policy 38(8), 4048-4056.

Gelabert, L., X. Labandeira, and P. Linares (2011). An ex-post analysis of the effect of renewables and cogeneration on spanish electricity prices. Energy Economics 33(1), S59S65.

Kwiatkowski, D., P. C. B. Phillips, P. Schmidt, and Y. Shin (1992). Testing the null hypothesis of stationarity against the alternative of a unit root: How sure are we that economic time series have a unit root? Journal of Econometrics 54(1-3), 159-178.

Ofgem (2008). Energy supply probe - initial findings report. Technical report.

Ragwitz, M., A. Held, G. Resch, T. Faber, R. Haas, C. Huber, R. Coenraads, M. Voogt, G. Reece, P. Morthorst, S. Jensen, I. Konstantinaviciute, and B. Heyder (2007). Assessment and optimization of renewable energy support schemes in the European electricity market. Report by order of the European Commission, DG Energy and Transport. Brussels, Belgium: European Commission.

Saenz de Miera, G., P. del Rio Gonzalez, and I. Vizcaino (2008). Analysing the impact of renewable electricity support schemes on power prices: The case of wind electricity in spain. Energy Policy 36 (9), 3345-3359.

Sensfub, F., M. Ragwitz, and M. Genoese (2008). The merit-order effect: A detailed analysis of the price effect of renewable electricity generation on spot market prices in germany. Energy Policy 36(8), 3086-3094. 
Traber, T. and C. Kemfert (2009). Impacts of the german support for renewable energy on electricity prices, emissions, and firms. The Energy Journal 30(3).

Traber, T. and C. Kemfert (2011). Gone with the wind? electricity market prices and incentives to invest in thermal power plants under increasing wind energy supply. Energy Economics 33(2), 249-256.

Würzburg, K., X. Labandeira, and P. Linares (2013). Renewable generation and electricity prices: Taking stock and new evidence for germany and austria. Energy Economics 40(1), S159-S171. 


\section{Appendix}

Eq.(A0) represents the weekly Retail Price $(R P)$ proxy as the result of adding the Access Tariff $(A T)$, Net Retail Margins $(N R M)$ and the Wholesale Cost $(W C)$.

$$
R P=A T+N R M+W C
$$

The $A T$ data comes from Spanish national regulatory agency (CNMC, previously named CNE) reports on monitoring the retail market ${ }^{11,12}$. The NRM, obtained from the same source, were compute quarterly by the CNMC based on two forward purchasing strategies by retailers (see CNE (2013)). We follow the same methodology for one the forward purchasing strategy to approach their $W C$ on rolling basis, but with weekly frequency. Below we explain first the actual dynamics of the Spanish future market products we used (weekly, monthly and quarterly), and second, the suppliers forward purchasing strategy used to compute the $W C$.

\section{Spanish future market products}

There are three products from the Spanish future market that we use to compute the WC based on the suppliers forward purchasing strategies; quarterly, monthly and weekly base load forward contracts. Each contract name corresponds to the delivery period, for instance Q4 is a contract delivered during the fourth quarter of the year (M1 is delivered during the first month, and W2 is delivered during the second week). The three products not only differed on the length of delivery, but also on the time between their first trading day and delivery period. As shown in Figure A1, while the first trading day of quarterly products starts one year before the delivery of the first quarter, for monthly products the first trading day is the first day one quarter before the quarter holding the month, and for weekly products is the first day three weeks before the delivery week.

Figure A1: Future market products

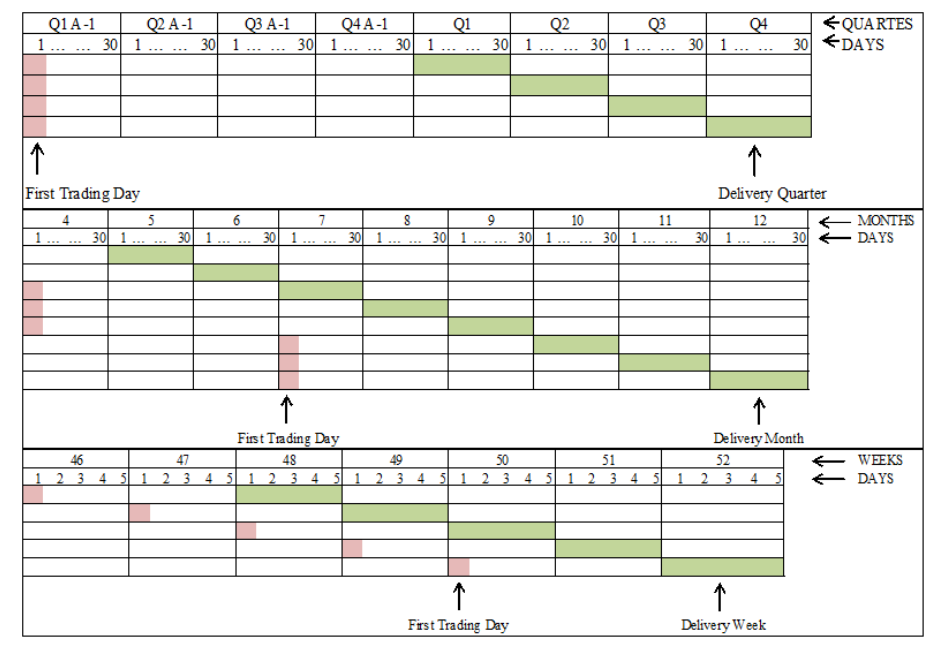

11 "Informe de Supervision del Mercado Minorista de Electricidad Julio 2011 - Junio 2012", (CNE (2013)) More precisely we used the CNMC access tariff for the average industrial consumer according to the RD 110/2007 consumers classification.

${ }^{12}$ The $A T$ includes the cost of transmission and distribution networks, market system interruptibility, extrapeninsular cost, special regime, and a portion of previous years imbalance between regulated income and costs, among others. In Spain, systematically the AT do not cover all the regulated costs. 


\section{Suppliers forward purchasing strategy}

We use the same methodology as CNMC for the forward purchasing strategy, consisting on combining products with different lengths. To obtain higher frequency for the $\mathrm{WC}$, in addition to the monthly and quarterly contracts used by the CNMC, we also take into consideration the weekly contracts. The strategy is a combination of weekly, monthly and quarterly products bought on rolling bases. Therefore, after computing the price for the three alternative products, we combined them to obtain the weekly WC by taking the average price of the three products during each week.

In this dynamic and rolling base strategy, the supplier buys during remaining time before the rolling period ends to cover the delivery. Hence, the price for each product is the resulting from covering one week ahead the delivery for each of the time horizons within the rolling period, weighted by the number of horizons remaining before the rolling period ends.

In the case of quarterly products, the price with this purchasing strategy is the resulting from covering one week ahead the delivery for each of the four quarter within the rolling year, weighted by the number of quarter remaining before the rolling year ends. Figure A2 provides the example of the purchasing strategy for Q4. The price of the coverage corresponding to Q4 is represented in Eq.(A1).

$$
P(Q 4 Y)=P 1 W(Q 1 Y) * 4+P 1 W(Q 2 Y) * 3+P 1 W(Q 3 Y) * 2+P 1 W(Q 4 Y) / 10
$$

Figure A2: Strategy for quarterly products (Q4 example)

\begin{tabular}{|c|c|c|c|c|c|c|}
\hline Q3 Y-1 & Q4 Y-1 & $\mathrm{Q1Y}$ & Q2Y & $\mathrm{QH}$ & Q4Y & $\leftarrow$ QUARTES \\
\hline 1. & 1. & $1 \ldots$ & $1 \ldots$ & 1. & & $\leftarrow$ DAYS \\
\hline & & & & & & H1 \\
\hline & & & & & & $\mathrm{H} 2$ \\
\hline & & & & & & H3 \\
\hline & & & & & & $\mathrm{H} 4$ \\
\hline
\end{tabular}

With monthly products, as in the case explained before, the price is the resulting from covering one week ahead the delivery for each of the three months within the rolling quarter, weighted by the number of month remaining before the rolling quarter ends. Figure A3 provides the example of the purchasing strategy for M12, and the price of the coverage corresponding to that month is represented in Eq.(A2).

$$
P(M 12)=P 1 W(M 10) * 3+P 1 W(M 11) * 2+P 1 W(M 12) / 6
$$

\begin{tabular}{|c|c|c|c|c|c|c|}
\hline 7 & 8 & 9 & 10 & 11 & 12 & $\leftarrow$ MOHTHS \\
\hline $1 \ldots \ldots$. & $\begin{array}{lll}1 \ldots & \ldots & 30\end{array}$ & $\begin{array}{lll}1 \ldots & \ldots \\
\end{array}$ & $\begin{array}{lll}1 \ldots & \ldots & 30\end{array}$ & $\begin{array}{lll}1 \ldots & \ldots & 30 \\
\end{array}$ & $\begin{array}{llll}1 & \ldots & \ldots & 30\end{array}$ & 0 \\
\hline & & & & & & $\mathrm{Hl}$ \\
\hline 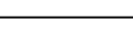 & 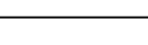 & & & & & $f_{\mathrm{H} 2}^{\mathrm{H} 2}$ \\
\hline
\end{tabular}

Figure A3: Strategy for monthly products (M12 example)

In the case of weekly contracts (see Figure A4) there are four weeks to be cover within each rolling month. Hence, following this strategy, the price corresponding the week 52 will be as represented in Eq.(A3). 


$$
P(W 52)=P 1 W(W 49) * 4+P 1 W(W 50) * 3+P 1 W(W 51) * 2+P 1 W(W 52) / 10
$$

Figure A4: Strategy for weekly products (W52 example)

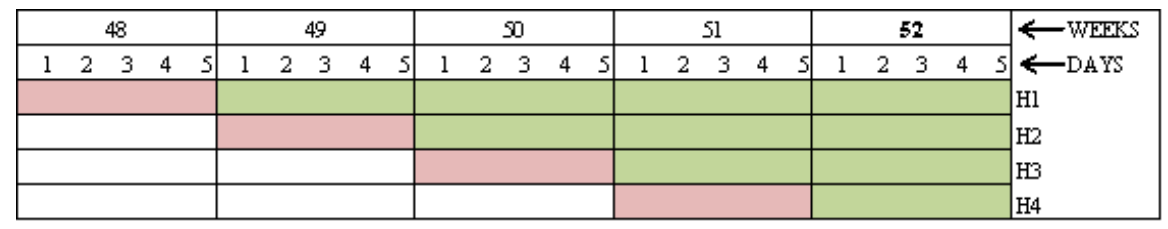

After computing the price for the three alternative products that can be buy by retailers to cover their supply each week, we combined them to obtain the WC by taking the average price for each week during the sample period. The WC corresponding to the example explained above as represented in Eq.(A4).

$$
W C(W 52)=P(Q 4 Y)+P(M 12)+P(W 52) / 3
$$

Finally, we combined the WC with the corresponding Net Retail Margins (NRM) (under the same purchasing strategy and time period), and the Access Tariff (AT) to compute the weekly Retail Price (RP). Eq. (A5) represents the retail price for the example week explained above:

$$
R P(W 52)=A T(Q 4)+N R M(Q 4)+W C(W 52)
$$

